\title{
How good are you at spotting tuberculosis (TB)?
}

Professor Peter D.O. Davies MA, DM, FRCP

Let's start with a quiz. The following are the numbers of deaths annually from these three diseases but they have got muddled up. Place the diseases opposite the correct number of deaths.

1.8 million

1.4 million

429,000

The correct answers are TB 1.8 million, malaria 429,000 and HIV/AIDS 1.4 million. In fact of those 1.4 million who die with HIV/AIDS 400,000 are also TB infected. ${ }^{1}$

DID you get that right? If so you scored better than $99 \%$ of the general population including a large number of medical people of all sorts, especially journalists.

In the Economist I was reading this week there is a four page article about the diseases of poverty and how they are being defeated. There was a lot about AIDS and Malaria, a little bit about the rarer tropical diseases but not a mention of TB. Why? Is it that these journalists are very very stupid people? They have probably all got first class degrees from their universities. Or that they are very very lazy and have done no research. Again these people are usually most assiduous to detail in their research. ${ }^{2}$

I think the real reason TB is not mentioned in such articles is that it never has been. Journalists in particular tend to copy what had gone before. When the millennium goals were first developed in 2000 the World Health Organisation (WHO) stated that the battle was against HIV/AIDS, TB and malaria. It was amazing how soon the tag became simplified to HIV/AIDS, malaria and other tropical disease. A leading article in The Times even substituted typhoid for TB.

The trouble is that this ignorance is passed on to doctors so that patients suffer or die as a result. I was recently involved in a case of an African lady, born and brought up in Africa who had come to the UK years previously. In her 60's she developed a neck gland which was biopsied and sent for histology but not culture. The result was that she was misdiagnosed and given the wrong treatment dying from overwhelming tuberculosis about eighth months later. While she was fading away her family told me she was tested three times for HIV but never for TB until it was too late.

The original biopsy was eventually sent for PCR (polymerase chain reaction) testing after her death and TB Bacterial DNA found to be present. How could the doctors treating her be so stupid? And there were whole teams of them who had been taken in.

Reading through her notes was so depressing. Every time she was admitted to hospital the wrong diagnosis was written almost with highlights at the start of the notes so that people reading the notes were bludgeoned into believing what was not true. I talked about this with a GP colleague and he said it was a clear case of railroad thinking. Once a particular course has been set even doctors are unprepared to question the very eminent team leader who had made the first diagnosis. They just carry on making the same error over and over again.
My wife and I used to own a bookshop. We are very keen on books especially novels. The novel is the most powerful weapon for change out of any reading material. One thinks of the effect that Dicken's description of Victorian London had on the improvement of the lot of the poorest in our land. An author who has gone out of fashion lately is A. J. Cronin. His books are said to have influenced William Beveridge in his repot of 1942 which led to the welfare state. Cronin's novel "The Citadel" should be made compulsory reading for all doctors I believe. At one point the hero of the story Andrew Manson has just taken his MRCP examination clearly passing with flying colours and almost as an afterthought one of the examiners asks him what the most important thing he has learned in medicine is. "To take no one's word for granted," was Manson's reply. If only at least one of the doctors who had been looking after that African lady could have thought of that mantra, events might have been different.

The list of risk factors for tuberculosis in low incidence countries reads as following in descending order of importance.

Origin in high TB incidence countries

History of homelessness incidence

History of illicit drug use

History of imprisonment

\section{HIV infection}

Other causes of immunosuppression.

Older age (living through a time when TB was common in the country. ${ }^{3}$

If only the doctors treating our patient had known this the patient might still be alive today. Instead they asked the useless question (useless if the answer is no) "Have you ever been in contact with someone with TB?" Only half of adults with TB actually admit to knowing someone with TB. This lady had spent 20 years in Africa, some of the time working as a nurse. Of course the first infection she was likely to get was TB. Incidentally look how low HIV infection comes in that list. Had the list looked at risk factors in Africa or even London then it would have been higher. But those are the importance of risk factors across all low incidence countries and being born and brought up in a high incidence country is the most important. Also that risk continues once the person has moved to the low incidence country and remains almost as high as though they had stayed in the country. So this lady developing a TB neck gland some 40 years after leaving Africa was no oddity. The phenomenon is well described in the literature.

So we have covered the epidemiology of the disease. What about the presentations. The trouble with TB is that it can present at any age and at virtually any site of the body but of course the lungs are the most common by far. 


\section{What are the symptoms of pulmonary tuberculosis?}

Cough sometimes with haemoptysis

Malaise

Weight loss

Night sweats

Breathlessness if advanced

\section{Chest pain}

The trouble is that none of these symptoms distinguish TB from any other lung infection. TB tends to be much more chronic though, symptoms developing over weeks or months. They can develop so gradually that sometimes about $1 / 3$ of the body weight can be lost before the patient starts to think something may be wrong.

Interestingly a statistical study has been carried out comparing $\mathrm{TB}$ with other lung infections and weight loss and night sweats did occur much more significantly in TB patients. ${ }^{4}$

Moving on to the examination, it always amazes me how much of the lung can be destroyed before examination of the lungs by auscultation throws up an abnormality. Of course TB can present with a pleural effusion and that should be obvious to percussion. But otherwise examination of the chest is frequently unrewarding.

Move on quickly to the key tests, which in a developed country will probably be a chest $\mathrm{x}$-ray to start with. In developing countries the chest $\mathrm{x}$-ray may be an expensive and unnecessary test. In about half of all pulmonary cases sputum smear for staining and microscopy, preferably three will throw up the diagnosis within in an hour or two. No culture facilities are available in most centres in developing countries but in developed countries all specimens will be cultured with liquid media using radioactive techniques to spot the growing bacilli early. The so called gene probe test is being rolled out across many developing areas enabling the diagnosis to be made quickly even in smear negatives cases and even drug resistance can be detected within a couple of hours.

So you have done all that and the answer comes back positive. Well done you have diagnosed a case of TB, but after that remember you are not on your own. A TB case becomes a public health problem as well as a clinician's problem, whether the case is infectious or not.

I am sure there will be a picture in every paediatric ward in the country of a small child seated on a potty and the caption will read. "Remember, the job isn't finished until the paper work is done." It's the same with TB. The law states that a person "Who believes a patient to be suffering from tuberculosis," has a duty to notify that case to the, now so called, Consultant for Communicable Disease Control. Note it does not require proof that the patient is infectious only the belief of the notifying person. ${ }^{5}$

By this time it is probably time to pass the patient on to your local chest physician and TB service. Most cases of TB can wait a few days to start treatment but a quick telephone call may give you confidence to start the patient on the quadruple therapy of isoniazid, rifampicin, pyrazinamide and ethambutol now conveniently packaged into one tablet; Voractive.

Well that was easy. Diagnosing TB can be as easy as falling off a $\log$ and much less painful. But it quite often is not, particularly when it occurs at a non-respiratory site. And there are as many non-respiratory sites that TB can crop up in as there are organs in the body. But the one you really have to watch out for is TB Meningitis (TBM). This is a killer or paralyser and can strike in just a few days but usually a week or two.

The first clue is usually the epidemiological background (see above). Then several days of symptoms that can come and go; headaches, stiff neck, photophobia are to watch out for but just chronic headache can be a symptom. The only way to be sure you are not missing it is hospital admission and lumbar puncture (LP). But then that can be far from straightforward. The typical LP in cases of TBM shows low glucose, high protein and a few white cells; very like a viral pneumonia. It is only in very advanced cases that the bugs can be identified by direct smear. The rule about TBM is if you think about it, once you have got the basic samples off for bacteriology then treat. Even a few hours wasted can be life threatening for the patient. Steroids are always indicated and treatment is for a year, unlike other sites where treatment is for six months provided the bugs are fully sensitive.

The next most serious site for TB is the spine. Here a missed diagnosis can lead to paraplegia and I have seen a worrying number of those in my time. Again the hallmark is chronicity. The usual symptom is back pain but continuing for weeks. Once the spine begins to collapse the danger of paraplegia is real so there should be no delay. A biopsy of the affected part under CT control and sending for culture as well as histology is the way forward.

But the commonest site for tuberculosis outside the lungs is the cervical glands. In patients of South Asian origin glandular TB is the commonest presentation, far more common than pulmonary TB. Again the symptoms are chronic and the glands may have been present for weeks before the patient presents. Biopsy for culture and histology is essential as was indicated by the patient case I described earlier. ${ }^{6}$

Actually getting a culture positive result from TB does not always happen. National statistics suggest that only just under half of all patients treated for non-respiratory tuberculosis have a positive culture. In 2016, 63\% of TB cases were culture confirmed; a higher proportion of pulmonary TB cases were culture confirmed compared with extra-pulmonary TB cases $(76 \%$ versus $48 \%)$. The proof is in the efficacy of treatment. ${ }^{7}$

I had one patient referred to me by my ENT colleague while walking across the hospital car park. He had this 50 year old lady with a swelling in the neck which he kept draining of pus but the swelling just kept coming back and the many samples of pus grew nothing. Send her to me I said. One thing though, she is a barrister. Oh we dread that word. But she came and despite the fact I had no positive evidence other than the lesion itself that it was TB I treated her as TB and she got better. I did do a Mantoux test though which was strongly positive.

Beware falling into the trap though; the Mantoux test and its successor the IGRA blood tests are tests for the presence of TB infection, not necessarily active disease.

You may have noticed that I have said nothing about 
children yet. Children are the problem when it comes to TB because in childhood pulmonary disease is usually smear and culture negative. The diagnosis is usually made by the characteristic changes of the chest $\mathrm{x}$-ray where unilateral enlarged hilar glands plus the presence of a positive Mantoux or IGRA test may be considered diagnostic.

So a quick resume of TB. The key to spotting it is to suspect it. Only those who don't think of it miss it with bad consequences for the patient and for themselves.

\section{REFERENCES}

1. http://www.who.int/mediacentre/factsheets/fs104/en/ WHO 2107. Accessed 24/10/17.

2. Anon. The economist Sept 14th 2017. Generation games. https://www.economist.com/news/international/ 21728905 -report-gates-foundation-spells-outbiggest-risks-future-progress-great? $z i d=301 \& a h=e 8 \mathrm{e}$ b01e57f7c9b43a3c864613973b57f Accessed 24/10/17.

3. Control of Tuberculosis in Low-incidence countries. Ibrahim Abubakar and Robert Aldridge. In Clinical Tuberculosis 5th edition Edits: PDO Davies, SB Gordon, G Davies CRCPress London and New York pp361-375.
4. https://www.nice.org.uk/guidance/ng33/chapter/ Recommendations\#active-tb NICE 2016 Accessed 24/10/17.

5. http://webarchive.nationalarchives.gov. uk/20130105053557/http://www.dh.gov.uk/prod_ consum_dh/groups/dh_digitalassets/@dh/@en/@ps/ documents/digitalasset/dh_114589.pdf. Department of health 2010. Accessed 24/10/17.

6. PDO Davies, SP Byfield, AJ Nunn et al. National Survey of Tuberculosis Notifications in England and Wales 1978-9. Report from the Medical Research Council Tuberculosis and Chest Disease Unit. Brit Med J 1980; 281: 895-898.

7. https://www.gov.uk/government/uploads/system/ uploads/attachment_data/file/654152/TB_Annual_ Report_2017.pdf page 29. Public Health England 2017 accessed 24/10/17.

Correspondence to:

Professor Peter D.O. Davies,

Liverpool Heart and Chest Hospital, Liverpool L14 3PE

\section{The 2017 Sir Richard Owen Lecture}

\section{Bryan Rhodes, Laura Shepherd}

Monday October 23rd was the date for the 7th Annual Sir Richard Owen lecture delivered by retired Consultant plastic surgeon Brian Morgan. To mark the occasion Mr. Morgan had decided to have a short exhibition of plastic surgery-inspired artwork in the Education centre. This required some careful planning but the foyer of the Education centre was transformed for 2 days into a magnificent art gallery featuring work by Henry Tonks, Dickie Orpen and 3 paintings by Mr Morgan himself. Mr Morgan's paintings featured the King's Cross fire, a patient with severe burns, and a surgeon harvesting a split skin graft with a Humby knife. The centerpiece of the exhibition was a beautiful and rarely seen 1945 pastel drawing of an operating theatre by Dickie Orpen.

$\mathrm{Mr}$ Morgan's lecture was a fascinating account of the development of plastic surgery into the separate surgical specialty it is today. The first world war clearly had a large part to play but so did New Zealand as 3 of the 4 pioneering surgeons were from the country.

The lecture began with an introduction to early accounts of facial reconstruction in India and Italy. It was the high number of servicemen with severe facial injuries that made the first world war so important to the history of plastic surgery. Harold Gillies had already developed an interest in facial surgery when WW1 started and was posted to Wimereux, near Boulogne, to work with a French dentist called Valadier. Valadier was pioneering reconstruction of the mandible and Gillies followed this with further experience in Paris with surgeon Hippolyte
Morrestin. On returning to England, Gillies persuaded the army's chief surgeon, William Arbuthnot Lane (the pioneer of fracture fixation) that a facial injury ward should be established at the Cambridge Military Hospital in Aldershot. Initially, injured servicemen were slow to arrive and Gillies sent a large number of address labels to the military Base Hospitals in France to help direct patients to his unit. It soon became clear that the ward wasn't sufficient to meet demand.

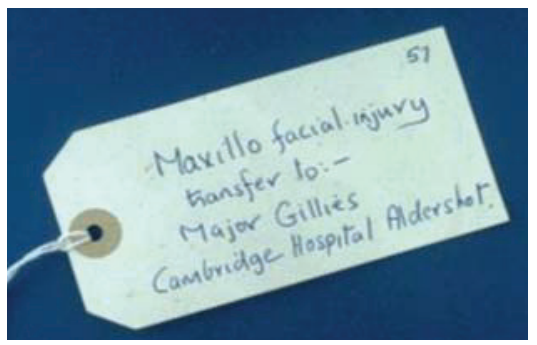

Address tag courtesy of Mr Morgan

Frognal house in Sidcup was a delapidated Jacobean mansion purchased by the Government in 1916. The House itself was converted into nursing accommodation and offices, and a hospital was built in the grounds. Huts connected by covered wooden walkways contained accommodation for junior doctors, operating theatres, $\mathrm{x}$-ray and medical illustration studios, laundry and kitchen facilities, chapel, cinema and canteen. The main wards were laid out in the shape of a horseshoe. The Queen's Hospital 